\title{
Effect of adding waste boulder powder on mechanical properties of green concrete
}

\author{
Xiaohui Li ${ }^{1, *}$ \\ ${ }^{1}$ CCCC Fourth Harbor Engineering Co., Ltd., Qingyuan 515000, Guangdong, China
}

\begin{abstract}
Reusing of stone powder formed in the production of manufactured sand is of great significance to environmental protection and resource utilization. In this paper, C30 and C40 environment-friendly manufactured sand concrete were prepared by adding $6 \%, 9 \%, 12 \%$ and $15 \%$ of waste boulder powder from manufactured sand production line into concrete and controlling the total weight of manufactured sand and rock powder to be constant. The influence of stone powder on concrete fluidity, compressive strength and elastic modulus were analysed. It was found that with the increase of stone powder content, the compressive strength of fresh paste and C30 concrete first increased and then decreased, while the elastic modulus of concrete and the compressive strength of $\mathrm{C} 40$ concrete continued to decrease. It is suggested that the content of rock powder should not exceed $9 \%$.
\end{abstract}

\section{Introduction}

With the increase in the scale of national infrastructure construction and the advancement of the "One Belt One Road" initiative, concrete raw materials, especially mineral admixtures, are in short supply in many regions. Fraud and adulteration of mineral admixtures (granulated blast furnace slag powder, fly ash, silicon ash, etc.) often occur, which greatly affects the quality of engineering construction. At present, many scholars are devoted to the research of new supplementary cementitious materials, such as limestone powder [1-4], metakaolin [5-9] and steel slag powder [10-13], to cope with current shortage of traditional mineral admixtures.

Phnom Penh-Sihanoukville Expressway (PPSE) is an important golden channel connecting Phnom Penh, the capital of Cambodia, to Sihanouk, the largest seaport in China and an external port. The construction of PPSE is of great significance for promoting the local economic development of Cambodia and implementing the "One Belt One Road" initiative. The starting point of PPSE is at the intersection of National Highway No. 4 and Phnom Penh City Circle Line in Cambodia, and the end point is on the No. 4 road on the edge of Sihanoukville. It is about $8.6 \mathrm{~km}$ away from Sihanoukville Port to the west and about $5.5 \mathrm{~km}$ away from Westport Economy, and it is about $8.5 \mathrm{~km}$ from Sihanoukville Airport. The total length is $187.05 \mathrm{Km}$. The whole line adopts Chinese highway construction standards and specifications. The design speed is $100 \mathrm{Km} / \mathrm{h}$, and the two-way four-lane.

The construction of PPSE also faces the problem of the lack of high-quality mineral admixtures and river sand resources. The project adopts the common boulder production manufactured sand along the project, and a large amount of rock powder of boulder is produced during the production process. If the boulder powder is recycled as mineral admixtures in engineering concrete production through research, not only could the pollution of the environment by the stacking of stone powder be solved, but also ordinary mineral admixtures could be replaced, and construction costs could be reduced. Hence, this paper studies the influence of different content of boulder powder on mechanical performance of concrete with different water-to-binder ratio and provides basic research data support for the application of boulder powder in engineering.

\section{Material and testing method}

\subsection{Raw material}

The apparent density of manufactured sand is $2650 \mathrm{~kg} /$ $\mathrm{m}^{3}$, the loose bulk density is $1630 \mathrm{~kg} / \mathrm{m}^{3}$, the porosity of loose bulk is $41 \%$, the content of stone powder is $10.2 \%$, the fineness modulus is 2.94 , the water demand ratio is $103 \%$, the MB value is 0.75 , and the maximum crushing index of single stage is $16.5 \%$. The crushed stone used is composed of $5-10 \mathrm{~mm}, 10-20 \mathrm{~mm}$ and $31.5 \mathrm{~mm}$ graded crushed stone with mass ratio of $2: 5: 3$. The content of needle flake particles is $0.6 \%$, and the maximum crushing index of single stage is $8.7 \%$.

The waste boulder powder was collected from the limestone manufactured sand production line and screened by $0.075 \mathrm{~mm}$ screen. The test results showed that the fluidity ratio was $106 \%$, the water demand ratio was $98.30 \%$, the MB value was 3.8, the specific surface area was $900.21 \mathrm{~kg} / \mathrm{m}^{3}$, the density was $2655 \mathrm{~kg} / \mathrm{m}^{3}$, the water content was $0.41 \%$, and the $7 \mathrm{~d}$ activity index was 90\%. Using P.O. 42.5 cement, standard consistency

\footnotetext{
* Corresponding author: 157906902@qq.com
} 
$27.1 \%$, specific surface area $326 \mathrm{~m}^{2} / \mathrm{kg}$, initial setting time $161 \mathrm{~min}$, final setting time $246 \mathrm{~min}$, 3d strength $32.2 \mathrm{MPa}, 28 \mathrm{~d}$ strength $57.5 \mathrm{MPa}$. Type F class II fly ash is used, with fineness of $13.2 \%$ ( $45 \mu \mathrm{m}$ sieve residue) and $28 \mathrm{~d}$ activity index of $74 \%$. Using polycarboxylate water reducer, the solid content is $30.2 \%$, and the water reducing rate is $28 \%$.

\subsection{Mix proportion}

Table 1 Mix proportion of influence of content of waste boulder powder on mechanical properties of concrete $\left(\mathrm{kg} / \mathrm{m}^{3}\right)$

\begin{tabular}{|c|c|c|c|c|c|c|c|}
\hline Sample ID & Cement & Fly ash & Manufactured sand & Waste boulder powder & Coarse aggregate & Water & W/B \\
\hline C30-S-6 & 294 & 74 & 750 & $48(6 \%)$ & 1058 & 162 & \\
\hline C30-S-9 & 294 & 74 & 726 & $72(9 \%)$ & 1058 & 162 \\
\hline C30-S-12 & 294 & 74 & 702 & $96(12 \%)$ & 1058 & 162 \\
\hline C30-S-15 & 294 & 74 & 678 & $120(15 \%)$ & 1058 & 162 & \\
\hline C40-S-6 & 341 & 85 & 765 & $49(6 \%)$ & 994 & 162 & \\
\hline C40-S-9 & 341 & 85 & 741 & $73(9 \%)$ & 994 & 162 & \multirow{2}{*}{0.38} \\
\hline C40-S-12 & 341 & 85 & 716 & $98(12 \%)$ & 994 & 162 & \\
\hline C40-S-15 & 341 & 85 & 692 & $122(15 \%)$ & 994 & 162 & \\
\hline
\end{tabular}

\subsection{Testing method}

The slump, slump-flow and air content of concrete were tested in accordance with the Chinese standard Standard for test method of performance on ordinary fresh concrete: GB/T 50080-2016; The compressive strength and static compressive elastic modulus of hardened concrete (hereinafter referred to as elastic modulus) are tested in accordance with the Chinese standard Standard for test method of concrete physical and mechanical properties: GB/T 50081-2019. The size of compressive strength test specimen was $100 \mathrm{~mm}$ cube, and the test age was $3 \mathrm{~d}, 7 \mathrm{~d}, 28 \mathrm{~d}$ and $56 \mathrm{~d}$. The test age of elastic modulus was $28 \mathrm{~d}$ and $56 \mathrm{~d}$.

\section{Result and discussion}

\subsection{Workability}

Fig. 1 showed the effect of waste boulder powder on the workability of manufactured sand concrete under different W/B and stone powder content. powder content increased from $6 \%$ to $15 \%$, the slump of fresh paste first increases and then decreased. When the stone powder content in $\mathrm{C} 30$ concrete exceeded $12 \%$, the slump decreased, and when the stone powder content in The relationship between slump, air content and slumpflow of fresh paste were quantitatively described in Fig. 2. In order to characterize the correlation between fresh concrete performance and stone powder content, the quadratic function model was used to regress the relationship between concrete fluidity, air content and stone powder content in Fig. 3. It was found that there was a significant quadratic function relationship between concrete slump, slump-flow, air content and stone
According to the change of slump, when the stone C40 concrete exceeded 9\%, the slump began to decrease.
The influence of waste boulder powder on the performance of manufactured sand concrete was shown in Table 1. The water-to-binder ratio (W/B) of 0.44 and 0.38 were designed respectively to prepare $\mathrm{C} 30$ and $\mathrm{C} 40$ strength grade concrete and compare the influence of $\mathrm{W} / \mathrm{B}$. The total weight of manufactured sand and waste boulder powder in $\mathrm{C} 30$ was $798 \mathrm{~kg} / \mathrm{m}^{3}$, and that in $\mathrm{C} 40$ was $814 \mathrm{~kg} / \mathrm{m}^{3}$. The amount of rock powder in brackets after the weight of rock powder was $6 \%, 9 \%, 12 \%$ and $15 \%$ respectively. powder content under different W/B, which confirmed the rule that the fluidity in Fig. 1 first increases and then decreases.

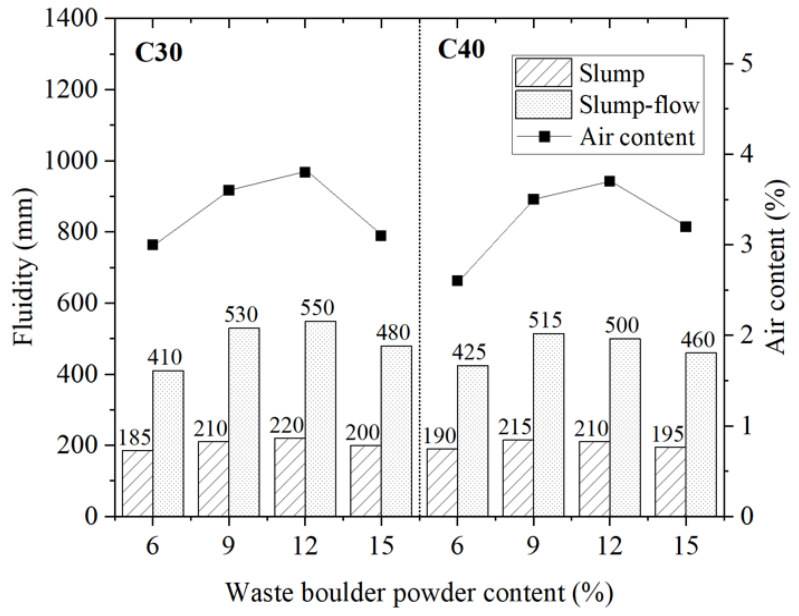

Fig. 1 Effect of waste boulder powder on workability of manufactured sand concrete

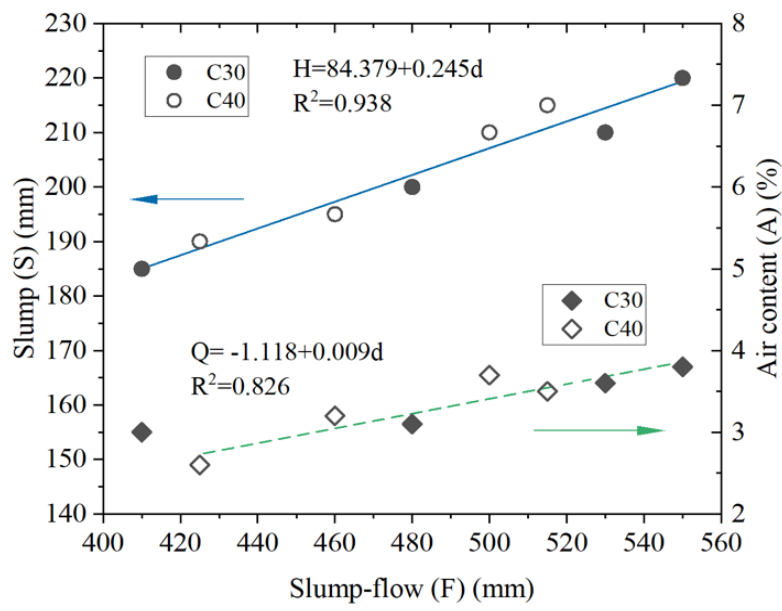

Fig. 2 Correlation of slump, air content and slump-flow of waste boulder powder concrete 
As a kind of calcareous powder, the biggest difference between limestone powder and granite, basalt and other rock powder lay in its small adsorption performance. According to the research [14,15], the surface energy of calcium carbonate in limestone powder particles was about $230 \times 10^{-7} \mathrm{~J} / \mathrm{cm}^{2}$. Low surface energy could reduce the water demand ratio of concrete with limestone rock powder, that is, reduce the water absorption of paste or have water reducing effect. Therefore, with the increase of calcareous rock powder content, the fluidity of concrete gradually increased, which was similar to the existing research results [1618]. However, the MB value of rock powder used in this paper reached 3.8, which reflected that the rock powder contains more clay debris to a certain extent. When the content of stone powder exceeded a certain extent, the strong adsorption impurities absorb a large amount of free water, which weakened the fluidity of the paste. At the same time, the specific surface area of stone powder reaches $900 \mathrm{~g} / \mathrm{cm}^{3}$, and more mixing water is needed to wet the surface of stone powder particles to form a water film, resulting in the decline of concrete workability.

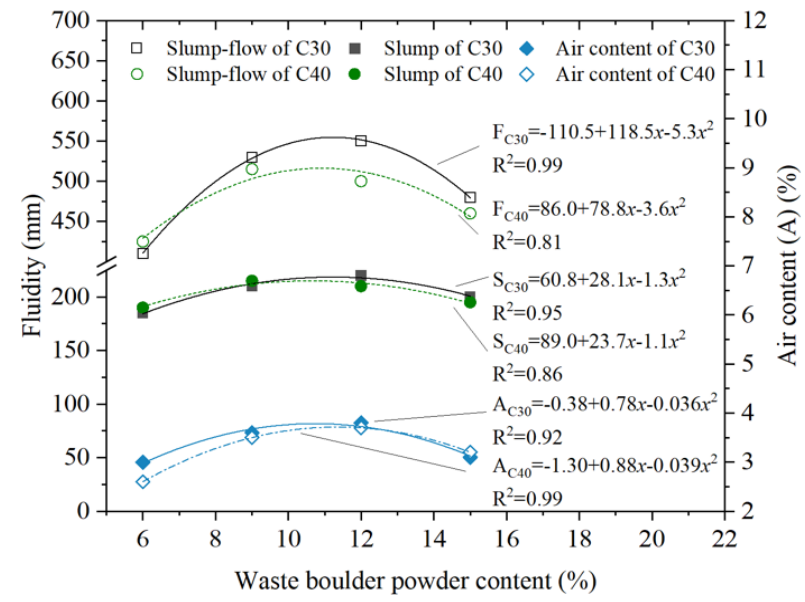

Fig. 3 Correlation between fluidity, air content and stone powder content of waste boulder powder concrete

\subsection{Compressive strength}

The experimental results of the influence of concrete prepared with waste boulder powder on its strength were shown in Figure 4. The solid line symbol represented C30 concrete, and the dotted line symbol represented $\mathrm{C} 40$ concrete.

With the increase of stone powder content, the strength of C30 concrete at different ages first increased and then decreased. The strength of C30-S-9 specimen was the highest at each age, and its 56d strength was 65.5MPa. Although the strength of C30-S-15 was low, its $56 \mathrm{~d}$ strength could still reach $61.1 \mathrm{MPa}$. It could be seen that the increase of stone powder content from $9 \%$ to $15 \%$ had little effect on the strength of $\mathrm{C} 30$ concrete. The strength of $\mathrm{C} 40$ concrete decreased with the increase of stone powder content. At 56d, the strength of C40-S-9 group was $70.8 \mathrm{MPa}$, and that of C40-S-15 group was $65.6 \mathrm{MPa}$. It could be seen that the weakening effect of stone powder content on the compressive strength of high strength concrete was more prominent. On the other hand, by comparing the strength data of concrete with different $\mathrm{W} / \mathrm{B}$ at the same age, it could be seen that the change of W/B had little effect on the early strength of concrete at $9 \%$ and $12 \%$ dosage.

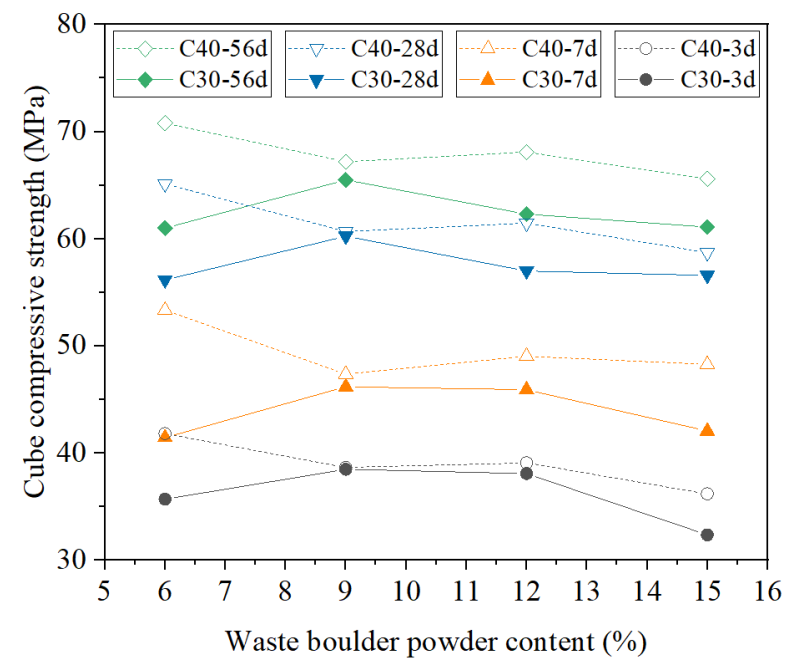

Fig. 4 Effect of waste boulder powder content on cube compressive strength of concrete

The influence mechanism of limestone powder on the mechanical properties of concrete has been widely studied, which could be divided into microcrystalline nucleation, micro aggregate and micro chemical action. Soroka et al. $[19,20]$ found that calcium carbonate powder particles could absorb the ions of hydration products, make C-S-H grow continuously on their own particle surface, promote the migration of $\mathrm{C} 3 \mathrm{~S}$ particle surface ions in cement clinker to aqueous solution, thus accelerate the hydration of $\mathrm{C} 3 \mathrm{~S}$, and significantly advance the nucleation time of $\mathrm{Ca}(\mathrm{OH})_{2}$.

Secondly, the stone powder particles with the maximum particle size less than $75 \mu \mathrm{m}$ could fill the voids between the cementitious material particles, replacing the excess free water existing in the voids, optimizing the particle accumulation mode, reducing the water consumption and average pore size [21], and improving the compactness of the slurry; At the same time, its tiny particles could play a "Ball Effect", improve the fluidity of the fresh slurry, and reduce the risk of large pores due to insufficient vibration in the moulding process.

In addition, limestone manufactured sand powder has weak chemical activity. According to the research of K. D. Weerdt et al. [22], micro particles of calcium carbonate powder will dissolve carbonate ions into the slurry aqueous solution, which could react with aluminum phase in Portland cement to form hard single carbon calcium carboaluminate and semi-carbon calcium carboaluminate, which will consume $\mathrm{Ca}(\mathrm{OH}) 2$, inhibiting the transformation of aft into AFm [23]. Finally, the average pore size of concrete paste is refined, and the strength of concrete is improved. These three kinds of actions make the early strength of manufactured sand concrete containing proper amount of stone powder increased rapidly. However, as a kind of inert material in the traditional sense, limestone rock powder itself could not provide outstanding cementitious and pozzolanic 
activity. Once the content of limestone rock powder was too high, its tiny particles will introduce too many low cohesive interface transition zone, which makes the slurry appear more thin and weak zone, resulting in the weakening of concrete hardening strength.

Therefore, for the concrete with different cementitious material dosage and strength requirements, there are differences in the optimal stone powder content of manufactured sand. As shown in Figure 4, the stone powder content of $\mathrm{C} 30$ concrete is about $9 \%$, and that of C40 concrete is about $6 \%$, which is close to the existing research [24].

\subsection{Elastic modulus}

The elastic modulus could reflect the constitutive relation of concrete after hardening, and it is an important mechanical property index of concrete. Table 2 showed the elastic modulus test results of waste boulder powder concrete. It could be seen that the elastic modulus of concrete will be slightly reduced when the content of manufactured sand powder increased from $9 \%$ to $15 \%$. Increasing the content of stone powder was equivalent to replacing the dense sand particles with loose powder particles, that is, the volume of concrete slurry increased, the content of coarse particles which play the main role of skeleton decreased, and the elastic modulus decreased. On the other hand, when the W/B increased, hydrated products contained more calcium silicate hydrate gel, and the microstructure of the slurry was denser, which was conducive to enhancing the elastic modulus of the slurry. When the W/B increased, there were more pores in the microstructure, higher air content, lower compactness and smaller elastic modulus.

Elastic modulus and compressive strength were important basic parameters of concrete, which were closely related to $\mathrm{W} / \mathrm{B}$, material composition, curing age and microstructure. Considering the uncertainty of concrete test, the effective prediction probability model of concrete elastic modulus was summarized based on compressive strength. Referring to the Chinese Standard Code for design of concrete structures (GB 50010-2010), formula (1) prediction model was adopted in many literatures.

$$
E_{c}=10^{5} /\left(2.2+34.7 / f_{c}\right)
$$

Where $f_{c}$ is the compressive strength of concrete, $E_{c}$ is the elastic modulus.

There were also many researchers using the power function model of formula (2), and the relevant institutions in Norway (NS) and the United States (ACI) recommend using formula (3) $\sim(5)$ respectively:

$$
\begin{array}{ll} 
& E_{c}=\left(a \times f_{c}^{0.5}+b\right) \times 10^{4} \\
\text { NS 3493: } & E_{c}=9.5 f_{c}^{0.3} \\
\text { ACI 363: } & E_{c}=3.32 f_{c}^{0.5}+6.9 \\
\text { ACI 318: } & E_{c}=4.73 f_{c}^{0.5}
\end{array}
$$

Where $f_{c}$ and $E_{c}$ have the same meanings as above. In equation (2), $a$ and $b$ are regression constants.

According to the test results and referring to equation (2), we used the power function model of equation (6) for regression analysis:

$$
E_{c}=40.6+1.1 \times 10^{-41} f_{c}^{22.7}
$$

It could be seen from Figure 5 that the regression curve of equation (6) was more consistent with the change rule of test data. In order to further analyze the calculation accuracy of formula (6) for the test results of each mix proportion specimen, the following prediction error was defined:

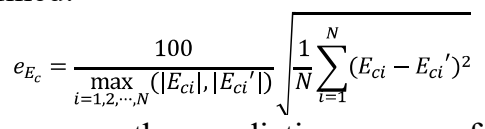

Where, $e_{E c}$ was the prediction error of concrete elastic modulus, \%; The subscript $i$ referred to the $i$-th mix proportion in Table 1, and $\mathrm{N}$ was the total number of mix proportion, which was taken as $8 ; E_{c i}$ and $E_{c i}$ ' were the measured value and calculated value of the elastic modulus of the $i$-th mix proportion specimen. The final calculation result of $e_{E c}$ in equation (6) was $2.65 \%$, in formula (1) formula (5) was $14.04 \%, 9.09 \%, 21.71 \%$, $21.10 \%$ and $11.79 \%$ respectively ( $a$ and $b$ in formula (1) was 0.26 and 1.8 respectively). It could be seen that the power function model (6) proposed in this paper had higher prediction accuracy.

Table 2 Effect of manufactured sand powder content on elastic modulus of concrete $(\mathrm{GPa})$

\begin{tabular}{|c|c|c|c|c|}
\hline Age/d & C30-S-9 & C30-S-15 & C40-S-9 & C40-S-15 \\
\hline 28 & 41.555 & 40.382 & 43.058 & 42.939 \\
\hline 56 & 42.197 & 40.952 & 44.646 & 43.391 \\
\hline
\end{tabular}

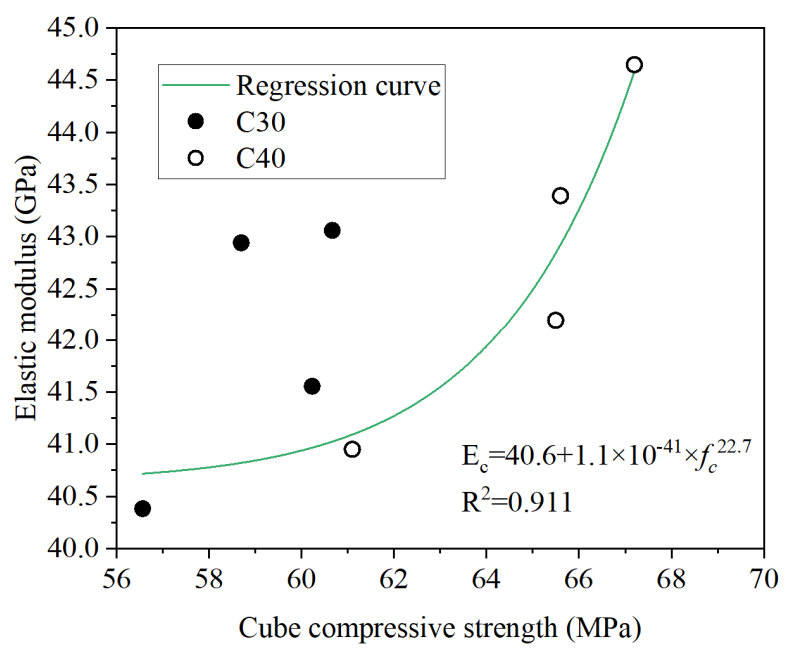

Fig. 5 Correlation between elastic modulus and cube compressive strength of concrete

\section{Conclusion}

In this paper, the waste boulder powder formed in the process of manufactured sand production was mixed into manufactured sand concrete by $6 \%, 9 \%, 12 \%$ and $15 \%$ respectively to prepare green environment-friendly concrete. The conclusions were as follows

(1) When the content of stone powder was more than $12 \%$, the fluidity of fresh paste could be improved, and the fluidity will be weakened if the content of stone powder was further increased.

(2) With the increase of stone powder content, the elastic modulus of hardened paste decreased, the compressive strength of $\mathrm{C} 30$ concrete first increased and 
then decreased, and the strength of C40 concrete continued to decrease.

(3) A mathematical model for predicting the elastic modulus of concrete by using the compressive strength of waste boulder powder was proposed, which had higher accuracy than the model in the existing specifications.

\section{Acknowledgements}

This research was funded by National Natural Science Foundation of China, grant number 51978408, and National Key R\&D Program of China, grant number 2016YFC0701000.

\section{References}

1. Palm Sebastian, Proske Tilo, Rezvani Moien, Hainer Stefan, Müller Christoph, and Graubner CarlAlexander, Constr. Build. Mater. 119, 308 (2016).

2. Proske Tilo, Rezvani Moien, Palm Sebastian, Müller Christoph, and Graubner Carl-Alexander, Cem. Concr. Compos. 89, 107 (2018).

3. Courard Luc and Michel Frédéric, Constr. Build. Mater. 51, 439 (2014).

4. Boubekeur Toufik, Boulekbache Bensaid, Aoudjane Kheireddine, Ezziane Karim, and Kadri El-Hadj, Constr. Build. Mater. 209, 215 (2019).

5. K. Scrivener, F. Martirena, S. Bishnoi, and S. Maity, Cem. Concr. Res. 114, 49 (2018).

6. Sánchez Berriel S., Favier A., Rosa Domínguez E., Sánchez Machado I. R., Heierli U., Scrivener K., Martirena Hernández F., and Habert G., J. Clean. Prod. 124, 361 (2016).

7. F. Avet and K. Scrivener, Cem. Concr. Res. 107, 124 (2018).

8. Dhandapani Yuvaraj, Sakthivel T., Santhanam Manu, Gettu Ravindra, and Pillai Radhakrishna G., Cem. Concr. Res. 107, 136 (2018).
9. Muzenda Tafadzwa Ronald, Hou Pengkun, Kawashima Shiho, Sui Tongbo, and Cheng Xin, Cem. Concr. Compos. 107, 103516 (2020).

10. S. Zhuang and Q. Wang, Cem. Concr. Res. 140, 106283 (2021).

11. D. Wang, Q. Wang, and Z. Huang, Compos. Part B Eng. 198, 108207 (2020).

12. Ji Yukun, Zhou Guoqing, Zhao Xiaodong, Wang Jianzhou, Wang Tao, Lai Zejin, and Mo Pinqiang, Cold Reg. Sci. Technol. 142, 25 (2017).

13. Wang Dengquan, Wang Qiang, and Xue Junfeng, Resour. Conserv. Recycl. 154, 104645 (2020).

14. W. D. Pratiwi, Triwulan, J. J. Ekaputri, and H. Fansuri, Constr. Build. Mater. 234, 117273 (2020).

15. J. Feng, F. Yang, and S. Qian, Constr. Build. Mater. 269, 121249 (2021)

16. L. Hu and Z. He, Constr. Build. Mater. 262, 119847 (2020).

17. J. Yu, H.-L. Wu, D. K. Mishra, G. Li, and C. K. Leung, J. Clean. Prod. 278, 123616 (2021).

18. H. Du and S. D. Pang, Constr. Build. Mater. 264, 120152 (2020).

19. I. Soroka and N. Stern, Cem. Concr. Res. 6, 367 (1976).

20. J. Péra, S. Husson, and B. Guilhot, Cem. Concr. Compos. 21, 99 (1999).

21. Y. Senhadji, G. Escadeillas, M. Mouli, H. Khelafi, and Benosman, Powder Technol. 254, 314 (2014).

22. K. De Weerdt, M. B. Haha, G. Le Saout, K. O. Kjellsen, H. Justnes, and B. Lothenbach, Cem. Concr. Res. 41, 279 (2011).

23. T. Matschei, B. Lothenbach, and F. P. Glasser, Cem. Concr. Res. 37, 551 (2007).

24. B. Li, G. Ke, and M. Zhou, Constr. Build. Mater. 25, 3849 (2011). 